\title{
Investigation of Chemomechanical Effects on Sapphire Surfaces Modified by Ion-Implantation-Induced Carbon Impurities
}

\author{
Arti Yadav $^{1} \cdot$ Noushin Moharrami $^{1} \cdot$ Steve Bull $^{1}$ iD
}

Received: 17 August 2020 / Revised: 4 February 2021 / Accepted: 11 February 2021 / Published online: 24 February 2021

(c) The Author(s) 2021

\begin{abstract}
Modification of the chemomechanical behaviour of the surface of sapphire by ion implantation to improve its near-surface mechanical properties has been investigated. $300 \mathrm{keV} \mathrm{Ti}{ }^{+}$ions at various doses were implanted and the concentration and damage profiles characterised using Rutherford Backscattering (RBS). At high doses $\left(\geq 3 \times 10^{16} \mathrm{Ti}^{+} \mathrm{cm}^{-2}\right)$, a surface amorphous layer is formed due to implantation-induced damage. Nanoindentation was used to determine the hardness behaviour of the ion-implanted layer. Hardness increases at low implantation doses, associated with implantation-induced damage, but it is also observed that chemomechanical softening of the surface is reduced due to the removal of adsorbed water. In situ Raman scattering measurements demonstrate this removal at low doses and the re-establishment of the adsorbed water layer at high doses. The adsorption process is changed due to the introduction of carbon into the sapphire surface during implantation. For the optimum-implanted dose, the water readsorption does not recur even several years after the implantation treatment was first carried out. The loss of water adsorption is related to the formation of a non-polar carbonaceous layer on the sapphire surface by cracking of back-streamed diffusion pump oil deposited on the sample surface by inelastic collisions with the ion beam. Based on this study, it is concluded that ion implantation with an appropriate ion species and dose can control the chemomechanical effect and improve the hardness of ceramics, such as sapphire.
\end{abstract}

Keywords Chemomechanical effects $\cdot$ Implantation $\cdot$ Mechanical properties $\cdot$ Sapphire

\section{Introduction}

Chemomechanical effects due to long-term environmental exposure are known to exert a considerable influence on the mechanical properties of ceramic surfaces [1-5]. Over past few decades studies have consistently reported that the mechanical properties, such as creep, fracture and fatigue have significant changes due to the test environment [6]. In particular, more recent studies have shown that the chemomechanical effect has significant influence on hardness in small-scale tests on various ceramic surfaces measured by high-resolution techniques, such as Nanoindentation [7-10]. This chemomechanical effect can be prevented by modifying the surface layer by ion implantation which is also expected to improve the surface mechanical properties under certain treatment conditions $[11,12]$. Surface modification of

Steve Bull

steve.bull@newcastle.ac.uk

1 School of Engineering, Newcastle University, Newcastle upon Tyne NE1 7RU, UK ceramic surfaces by ion implantation has been investigated to tailor the mechanical properties of the thin surface layers for tribological applications [11-13]. However, there are several important issues, such as the introduction of radiation damage, amorphisation and surface stress generation which operate independent of the any chemomechanical effects and can affect the tribological properties. Thus, to optimise a ceramic surface for tribological performance it is essential to consider both the treatment conditions and the operating environment.

Although the existence of chemomechanical effects in ceramic materials has been widely reported in the literature [14-16], less work has been done on the mechanisms by which environment-induced changes in near-surface region affect the mechanical properties of ceramics. Recently Bull et al. [9] studied the environmental effects on several ceramic materials using nanoindentation and atomic force microscopy and they observed a very thin adsorbate-modified layer $(\sim 1 \mathrm{~nm})$ appears in almost all the ceramic materials. In some crystalline materials, a second adsorbate-modified layer was observed with greater thickness (about $10 \mathrm{~nm}$ in 
crystalline materials like sapphire and $\mathrm{ZnO}$ ), which leads to noticeable softening of the surface in nanoindentation tests. The softening effect is associated with changes in surface charge and electronic structure due to adsorption that result in an increase in near-surface dislocation mobility $[9,11]$. It has been reported that ion implantation reduces the chemomechanical effect as it modifies the band structure of the surface by the introduction of point defects and implanted atoms. This occurs at doses well below when radiation hardening is observed in oxide ceramics [12].

Ion implantation is a surface treatment process whereby energetic ions are accelerated through 50 to $500 \mathrm{keV}$ and penetrate the surface of a target material $[11,12,17]$. Therefore, this process changes both the composition and microstructure of the near-surface region and results in changes of chemical and physical properties [18]. Ion implantation has been used to improve the adherence of coatings on ceramic surfaces [19]. The typical layer thickness for ion implantation in ceramics is usually less than $1 \mu \mathrm{m}$ and therefore it is an attractive process to control the surface mechanical properties when wear processes generate a low surface removal rate with wear depth and surface penetration of less than half a micron. It has been reported that low dose ion implantation increases the hardness of a crystalline material by reducing dislocation mobility due to the presence of both implanted atoms and defects created as the implanted ions come to rest in the material (radiation hardening). However, ion implantation of ceramic materials can lead to either nearsurface hardening or softening $[19,20]$. The hardening is attributed to combination of radiation hardening and solid solution effects as above whilst the softening is usually a consequence of amorphization.

In this work, we systematically investigated how the chemomechanical behaviour of sapphire changes after $\mathrm{Ti}^{+}$ion implantation. $300 \mathrm{keV} \mathrm{Ti}^{+}$ions have been implanted into single crystal sapphire with a range of doses. The nanoindentation hardness is highly dependent on the implanted dose and the environment is only important in a critical dose range where removal of adsorbed water layer has occurred. Thus, treating the surface with appropriate ion implanted species can control the near-surface hardness and reduce the chemomechanical effect which is required for optimum tribological performance.

\section{Methodology}

\subsection{Sample Preparation}

The single crystal sapphire $\left(\begin{array}{lll}10 & \overline{1} & 2\end{array}\right)$ substrates were obtained from GEC and cleaved into smaller sizes of $10 \times 10 \times 0.5 \mathrm{~mm}$. Prior to implantation, the specimens were carefully ultrasonically cleaned degreased in isopropyl alcohol. The specimens were implanted with titanium $(300 \mathrm{keV})$ to doses in the range from $2 \times 10^{16}$ to $1.5 \times 10^{17} \mathrm{Ti}^{+}$ $\mathrm{cm}^{-2}$ in the Cockcroft-Walton facility at UKAEA Harwell. All implantations were carried out at room temperature with a beam current of few microamps per centimetre squared; beam heating was estimated to be about $250{ }^{\circ} \mathrm{C}$. Under these conditions the ion range is $159 \mathrm{~nm}$ and its straggle is $43 \mathrm{~nm}$ according to calculations using the SRIM program [21]. The depth of maximum damage is at $126 \mathrm{~nm}$ and the sputtering yield is 2.6.

\subsection{Rutherford Backscattered (RBS)}

The ion depth profiles were evaluated using $2.0 \mathrm{meV}$ $\alpha$-particle Rutherford Backscattering (RBS) spectra measurements with the sample normal oriented at about $7^{\circ}$ to the analysis beam direction. This generates the spectrum from a "randomly oriented" sample. Channelled RBS was then used to determine the profile of damage caused by the implantation. In this case, the [0001] channel at about $58^{\circ}$ to the surface normal was aligned with the beam direction. In this orientation, the open channels in the crystallographic structure are aligned with the analysis beam and penetration of the beam is increased and backscattering is reduced. Only when damage disrupts the channel will the backscattered signal increase.

\subsection{Nanoindentation}

To characterise the near-surface mechanical properties of the sapphire with different doses of implantation, nanoindentation experiments were performed in the displacement-controlled mode using a Hysitron Triboindenter nanoindentation system fitted with a sharp Berkovich indenter (tip end radius $100 \mathrm{~nm}$ ). To investigate the environment effects that influence the hardness, the nanoindentation tests were performed on the same sapphire sample after soaking the surface in ethanol or water for $24 \mathrm{~h}$. After the samples were removed from the liquids, they were dried immediately at $50{ }^{\circ} \mathrm{C}$ using a hot air blower. Indentation tests were performed immediately after drying. An array of twenty indents was created on every sample.

\subsection{Raman Spectroscopy}

It is known that chemomechanical effects arise from the presence of surface adsorbates and the magnitude of the effect is directly proportional to the adsorbate concentration. To evaluate the surface water concentration for single crystal sapphire, Raman spectroscopy was used. Raman analyses were performed using a confocal microscope (Horiba HR800) with $632 \mathrm{~nm}$ excitation. The calibration of the wavelength was done prior to the experiment with a silicon 
standard. Raman spectra of all the samples were measured in situ in air, ethanol and water. The laser beam was focussed on the samples with the $50 \times$ objective in all cases. First, a Raman spectrum was measured for all the samples in air. Then, the samples were then placed in a shallow container (petri dish) with ethanol for $24 \mathrm{~h}$ and the Raman experiments were repeated with the samples still in the ethanol (i.e. under liquid). After that the samples were removed and rinsed several times with de-ionised (DI) water. Following this the samples were placed in DI water in a petri dish for $24 \mathrm{~h}$ and then Raman experiments were repeated under this new liquid. The same area was selected in each case and nine $(3 \times 3)$ spectra were collected in the wavenumber range of $2500-3500 \mathrm{~cm}^{-1}$ where peaks due to water are observed. All experiments were conducted at room temperature. The nanoindentation results were correlated with the structural changes measured by Rutherford backscattering and in-situ Raman.

\subsection{X-Ray Photoelectron Spectroscopy (XPS)}

After implantation and prior to soaking in water or ethanol, the chemical compositions and valence states of sapphire and sapphire implanted with Ti were studied by X-ray photoelectron spectroscopy measurements (XPS). All the spectra were acquired with a Kratos Axis Nova spectrometer. The samples were mounted on a clean $\mathrm{Al}$ platen and immobilised with carbon tape and copper clips. The largest analysis area available in the instrument $(300 \times 700 \mu \mathrm{m})$ was used in all the measurements. All measurements were repeated on three different analysis positions with non-overlapping analysis areas on each sample. Charge compensation was used throughout the measurement. The XPS spectra were analysed using the Casa XPS software.

\subsection{Water Contact Angle}

Surface polarity and changes to surface energy after implantation were investigated using water drop contact angles measured using an optical tensiometer. Prior to testing surfaces were cleaned with isopropyl alcohol and a $10 \mu \mathrm{L}$ drop of deionised water was used for measurement in each case. Five drops were measured on different areas of each surface tested, and the results were averaged.

\section{Results and Discussion}

\subsection{Characterisation of the Implant Profiles and Damage}

RBS was used in order to determine both the depth distribution of the implanted ions and the damage created as they come to rest [21]. The channelled RBS was used to ascertain if the implanted sapphire surfaces had been rendered amorphous (due to the accumulation of radiation damage). To achieve this RBS is used to determine both random and channelled profiles. When these coincide, the crystallographic channel is destroyed and amorphisation has occurred.

Figure 1 shows the typical RBS spectra $\left(2-\mathrm{meV}, 4 \mathrm{He}^{+}\right)$ from unimplanted single crystal sapphire and surfaces implanted with $\mathrm{Ti}^{+}$ions to doses of $3.2 \times 10^{16} \mathrm{Ti}^{+} \mathrm{cm}^{-2}$, $6.3 \times 10^{16} \mathrm{Ti}^{+} \mathrm{cm}^{-2}$ and $1.5 \times 10^{17} \mathrm{Ti}^{+} \mathrm{cm}^{-2}$. The random and channelled spectra from both the unimplanted and implanted surfaces are displayed as a function of the counts (yield) of back scattered particles with respect to the energy channel of the detector. The energy scale has been converted to a depth scale for $\mathrm{Ti}, \mathrm{Al}$ and $\mathrm{O}$ in sapphire using the RUMP software [22]. Because the mass differences between $\mathrm{Ti}, \mathrm{Al}$ and $\mathrm{O}$ are very large, the kinematics of the RBS process produce characteristic steps in the yield of particles that are scattered from the matrix elements ( $\mathrm{Al}$ and $\mathrm{O})$ and also a separate peak for scattering from the implanted titanium. Figure 1a presents the random and (10 12) channelled RBS spectra from the unimplanted sapphire surface. It can be observed that the random spectrum does not coincide with channelled spectrum. In the channelled spectrum, peaks due to scattering from $\mathrm{Al}$ and $\mathrm{O}$ atoms in the near-surface region are observed at about energy channels 300 and 180, respectively. The crystal quality of the starting material can be determined from the ratio of the channelled scattering yield to the random scattering yield just below the two surface peaks. In this case, for $\mathrm{Al}$ the aligned yield is $~ 50 \%$ of the random yield and for $\mathrm{O} \sim 55 \%$, which indicate that the single crystalline sapphire surface is almost damage free as might be expected for semiconductor-grade material. The effect of implanting $\mathrm{Ti}^{+}$(to $3.2 \times 10^{16} \mathrm{Ti}^{+} \mathrm{cm}^{-2}$ ) into the sapphire is shown in Fig. 1b. Comparing the (0001) channelled yields from the implanted and unimplanted regions, a substantial disorder has been introduced in both the $\mathrm{Al}$ and $\mathrm{O}$ subarrays. The amorphisation dose in this material is estimated to be $2 \times 10^{16} \mathrm{Ti}^{+} \mathrm{cm}^{-2}$ [19]. Amorphisation usually starts below the surface at the peak of damage caused by implantation and then spreads to the surface as the ion dose increases. When implanting $3.2 \times 10^{16} \mathrm{Ti}^{+} \mathrm{cm}^{-2}$, the random and channelled spectra do not coincide and there is also no significant change in the damage distribution. This indicates that the near-surface region has not become amorphous as the channelled yield after implantation does not reach the random yield value. In addition, it should be noted that the channelled spectrum shows a much lower yield than the random spectrum which is essentially indicating that the specimen is undamaged. The fact that sapphire is not turned completely amorphous at these implantation doses may be due to the existence of a reordering process during implantation [17, 
(a)

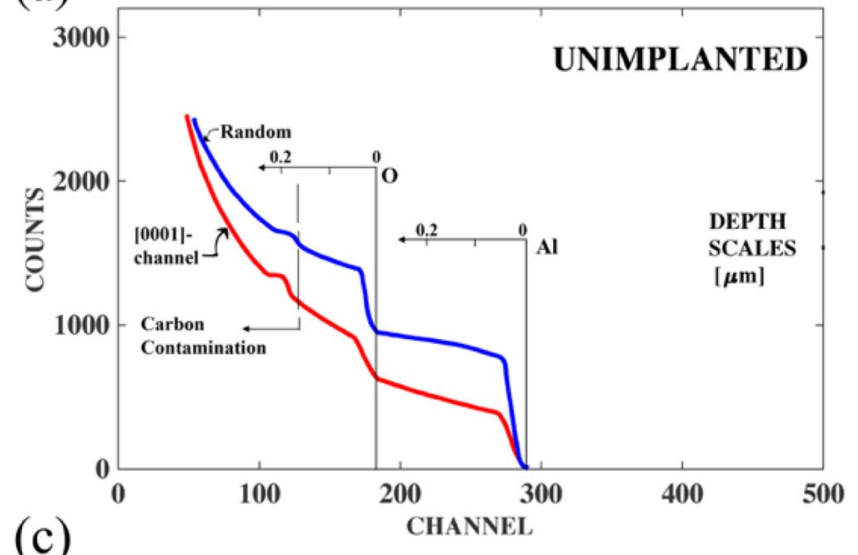

(c)

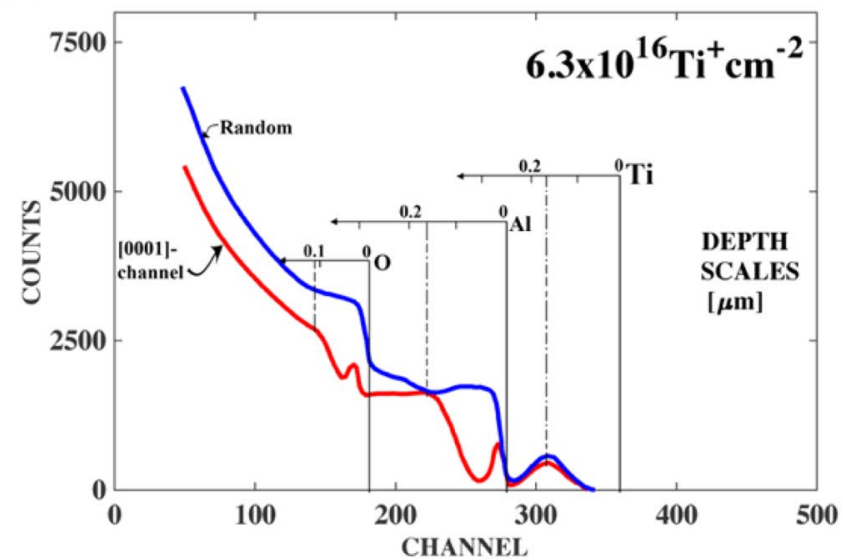

(b)

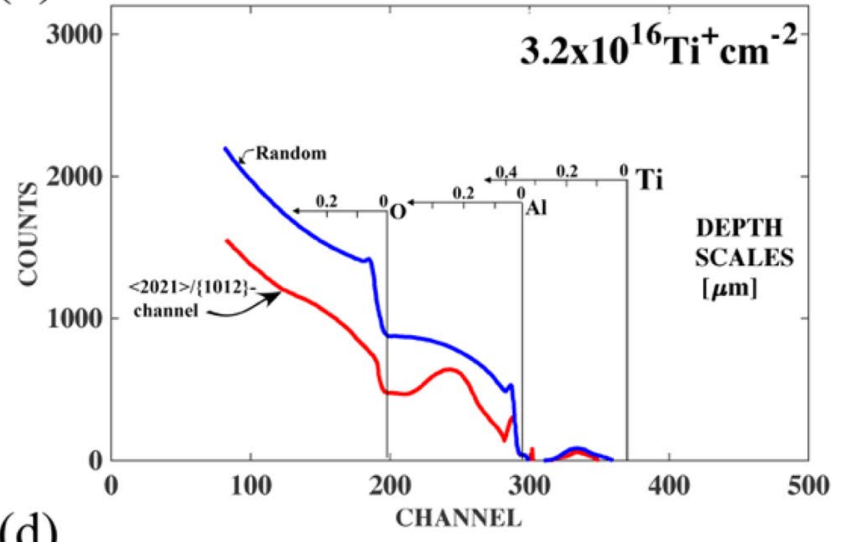

(d)

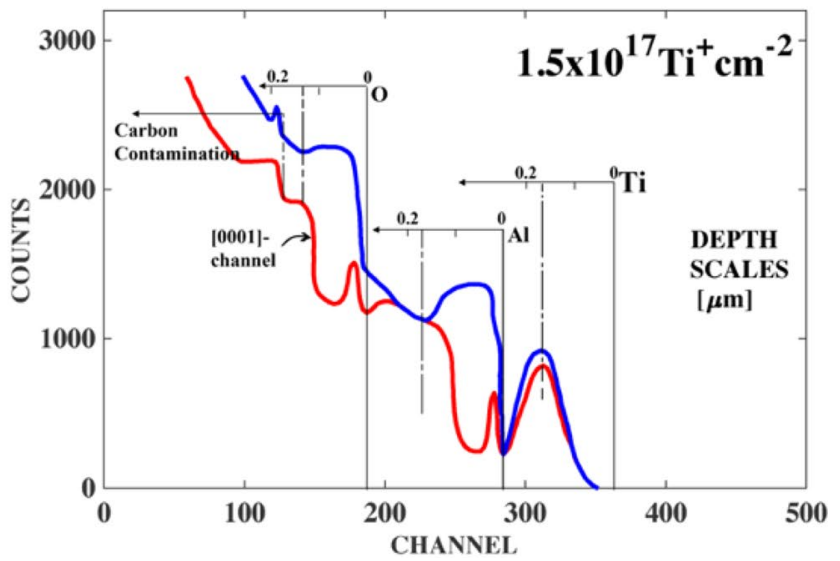

Fig. 1 A sequence of channelled and random RBS spectra obtained from sapphire a unimplanted, b implanted with $3.2 \times 10^{16} \mathrm{Ti}^{+} \mathrm{cm}^{-2}, \mathbf{c}$ implanted with $6.3 \times 10^{16} \mathrm{Ti}^{+} \mathrm{cm}^{-2}$ and $\mathbf{d}$ implanted with $1.5 \times 10^{17} \mathrm{Ti}^{+} \mathrm{cm}^{-2}$

19] as a consequence of the temperature rise of the sapphire sample during the treatment.

Figure 1c shows the random and channelled spectra for the implantation dose of $6.3 \times 10^{16} \mathrm{Ti}^{+} \mathrm{cm}^{-2}$ in sapphire. The peak in the titanium concentration profile occurs at a greater depth which is evidence that amorphisation has occurred (ions travel a greater distance in amorphous material with lower density). At this dose, the surface peaks from $\mathrm{Al}$ and $\mathrm{O}$ are considerably larger than in the case of previous doses. The near-surface region (just behind the surface peak) is damaged and shows complete amorphisation. The increased dose is found to broaden the damage profile to greater depths with very minimal or no increase in the magnitude of the damage levels. The depth at which the damage saturates in the $\mathrm{Al}$ subarray corresponds reasonably well with the peak of the Ti distribution. The implanted Ti shows a small channelling effect (the channelled yield is $\sim 88 \%$ of the random yield). In addition, the implanted peak (for an ion of mass greater than the target) may also show a reduced yield for the channelled spectrum if the ions occupy preferred structural sites [21]. An RBS spectrum from sapphire implanted with
$\mathrm{Ti}^{+}$ions to a dose of $1.5 \times 10^{17} \mathrm{Ti}^{+} \mathrm{cm}^{-2}$ is shown in Fig. $1 \mathrm{~d}$. It is observed that both the random and channelled spectra coincide with each other and significant disorder in both the $\mathrm{Al}$ and $\mathrm{O}$ subarrays is observed. Ti becomes highly substitutional in the lattice. The near-surface region is completely damaged. The damage is visible in the $\mathrm{Al}$ and $\mathrm{O}$ subarrays and there is no evidence of a peak of $\mathrm{O}$ concentration below the surface. Nevertheless, the Ti peak is found to be still Gaussian. Thus with increasing dose more and more damage is produced.

To summarise, at the low doses both the random and channelled spectra do not coincide whereas for the higher doses they coincide which implies that an amorphous layer has been formed at high doses. None of the specimens had been rendered amorphous at low doses, this being in agreement with earlier work [17]. The damaged regions become more predominant as the dose increases. For all the implanted species, we have not observed a completely disordered surface region up to doses of $6.3 \times 10^{16} \mathrm{Ti}^{+} \mathrm{cm}^{-2}$, whereas doses of $1.5 \times 10^{17} \mathrm{Ti}^{+} \mathrm{cm}^{-2}$ would be sufficient to turn the near-surface region completely amorphous. In all 
cases a little damage is visible in the $\mathrm{Al}$ and $\mathrm{O}$ subarrays and the Ti implanted peak remains approximately Gaussian. As the implantation doses are increased the implanted profile moves away from the surface which is due to the transformation from crystalline to amorphous surface with lower density [23].

\subsection{Nanoindentation Measurements}

In our previous studies we have shown that the near-surface hardness of sapphire for both micro- and nanoindentation is reduced after exposure to water and this reduction in hardness was consistent in both techniques. In contrast, the hardness is found to increase after exposure to ethanol or methanol as the contact depth is reduced. This is the result of the normal "indentation size effect" which is usually found when testing across different length scales in ceramics [23, 24]. However, the reduction in surface hardness after exposure to the water was directly associated with a soft water adsorbate-affected surface layer [24]. The indentation size

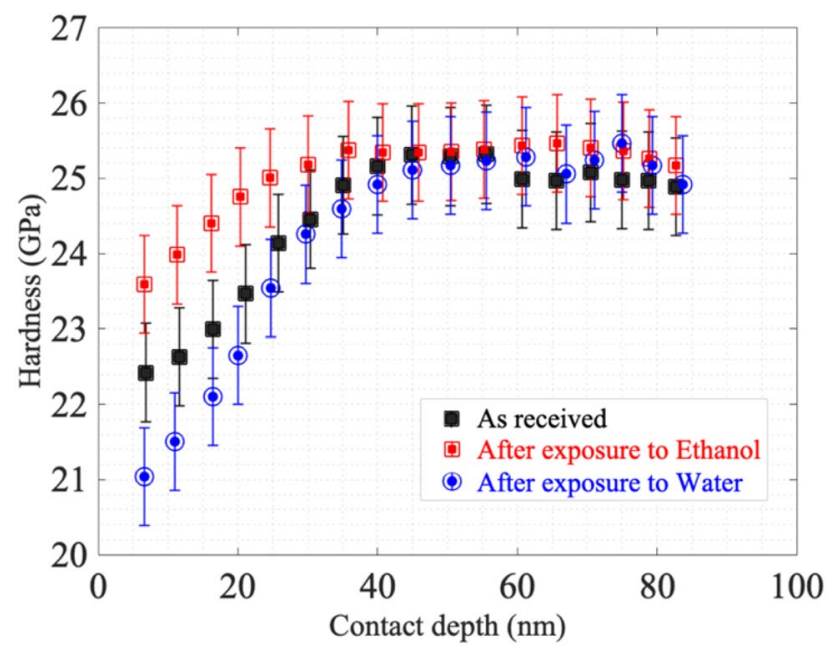

Fig. 2 Hardness of sapphire measured using nanoindentation as received and after exposure to methanol and water for $24 \mathrm{~h}$ effect hardening can be completely removed or even reversed due to this chemomechanical effect.

Figure 2 shows the hardness of single crystal sapphire measured using nanoindentation on as received samples and after soaking in methanol for $24 \mathrm{~h}$, followed by immersing in water for $24 \mathrm{~h}$. It is observed that in all three cases (i.e. air, ethanol and water), initially hardness is relatively low and increases with contact depth and saturates after the contact depth of about $40 \mathrm{~nm}$. This clearly indicates that the surface has become soft which is likely due to water adsorption on the surface. From the figure, it is seen that there is a significant increase in hardness at low contact depth below $40 \mathrm{~nm}$ when exposed to ethanol whereas the hardness is less when exposed to water. The hardness after soaking in water for $24 \mathrm{~h}$ is found to be even lower than the as received samples which have been exposed to humid air for many months. At the contact depth of $\sim 10 \mathrm{~nm}$, the hardness was $\sim 23 \mathrm{GPa}$ for ethanol exposure, but for water exposure it was $\sim 21 \mathrm{GPa}$. Such time-dependent changes in hardness and plasticity are associated with water adsorption [9]. A significant drop in the hardness after soaking in water for $24 \mathrm{~h}$, indicates the formation of a soft adsorbate-affected layer on the sapphire surface of a few nanometres in thickness.

The comparisons between the hardness of sapphire after exposure to ethanol and water for samples implanted with the doses of $1 \times 10^{16} \mathrm{Ti}^{+} \mathrm{cm}^{-2}$ and $2.5 \times 10^{16} \mathrm{Ti}^{+} \mathrm{cm}^{-2}$ are shown in Fig. 3. The hardness at the high dose $\left(2.5 \times 10^{16}\right.$ $\left.\mathrm{Ti}^{+} \mathrm{cm}^{-2}\right)$ is higher than that from samples implanted with low dose $\left(1 \times 10^{16} \mathrm{Ti}^{+} \mathrm{cm}^{-2}\right)$. Furthermore, from the figure, it is observed that there is a significant drop in hardness after exposure to water whereas this is not seen in the case of the $2.5 \times 10^{16} \mathrm{Ti}^{+} \mathrm{cm}^{-2}$ dose (Fig. 3a, b). This suggests that the adsorbed water is removed at a dose of $2.5 \times 10^{16} \mathrm{Ti}^{+} \mathrm{cm}^{-2}$ and adsorbate-induced increases in dislocation mobility are hence reduced. The effect of removal of any chemomechanical softening at low doses is much greater than any solid solution or radiation damage hardening from the implantation process. At high doses, the specimen surface is rendered amorphous and such dislocation-based mechanisms cannot
Fig. 3 Comparison in hardness vs contact depth after ethanol and water exposure for sapphire samples implanted with $\mathbf{a} 1 \times 10^{16} \mathrm{Ti}^{+} \mathrm{cm}^{-2}$ and $\mathbf{b}$ $2.5 \times 10^{16} \mathrm{Ti}^{+} \mathrm{cm}^{-2}$
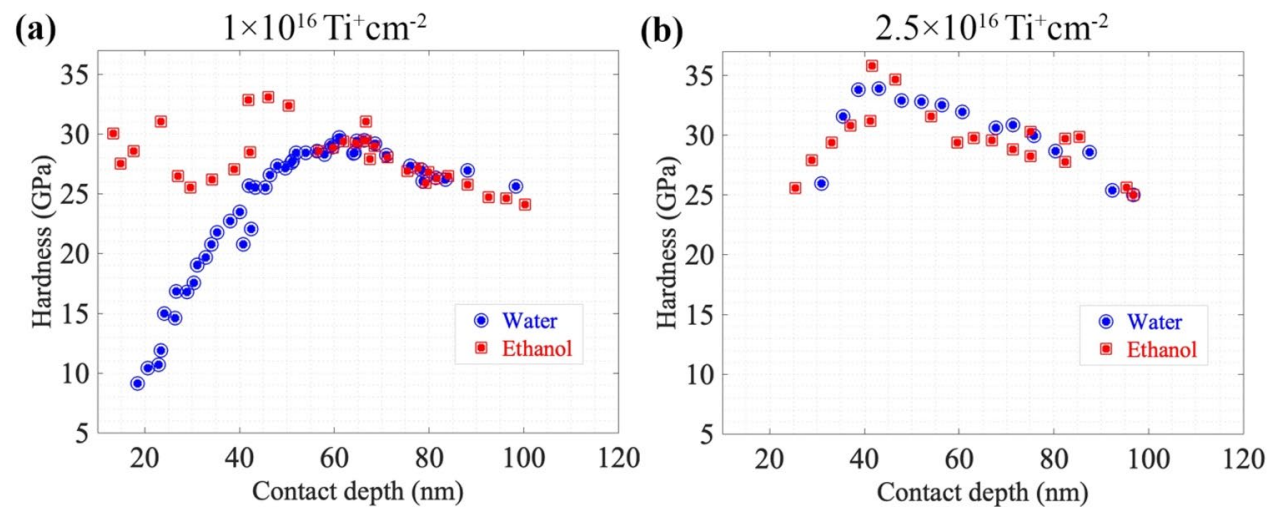
operate. Also, a thick water adsorbate layer can form on the sample due to the long-term effect of the environment.

As we have seen from the above (Figs. 2, 3) the hardness changes only below the contact depth of $40 \mathrm{~nm}$. Therefore, we have compared the hardness at this threshold contact depth $(40 \mathrm{~nm})$ for samples with different $\mathrm{Ti}^{+}$ion implantation doses (Fig. 4) after ethanol and water exposure. The hardness at low doses $\left(<3 \times 10^{16} \mathrm{Ti}^{+} \mathrm{cm}^{-2}\right)$ is higher and starts decreasing as the implantation dose increases which is associated with the onset of amorphisation (subsurface amorphous). It decreases further as the implantation dose reaches $10^{17} \mathrm{Ti}^{+} \mathrm{cm}^{-2}$ and eventually it becomes almost constant which is the regime of complete surface amorphisation. In water, after low dose $\mathrm{Ti}^{+}$ion implantation the hardness of the implanted sapphire is increased in comparison to unimplanted sapphire. This is to be expected mainly due to the reduction in the chemomechanical softening effect after implantation although a relatively small radiation damage hardening contribution might also contribute.

\subsection{Changes in Adsorbate Concentration After Implantation}

Many studies have proposed mechanisms for chemomechanical effects $[5,14,22,25]$. Although several possible explanations of the phenomenon have been suggested, it is still not certain which mechanisms are valid or determine behaviour in any particular case. Even so, the chemomechanical effect is significant and it affects the mechanical properties of ceramic materials as we have reported previously $[9,26]$. In our pervious study we have postulated that a thick water

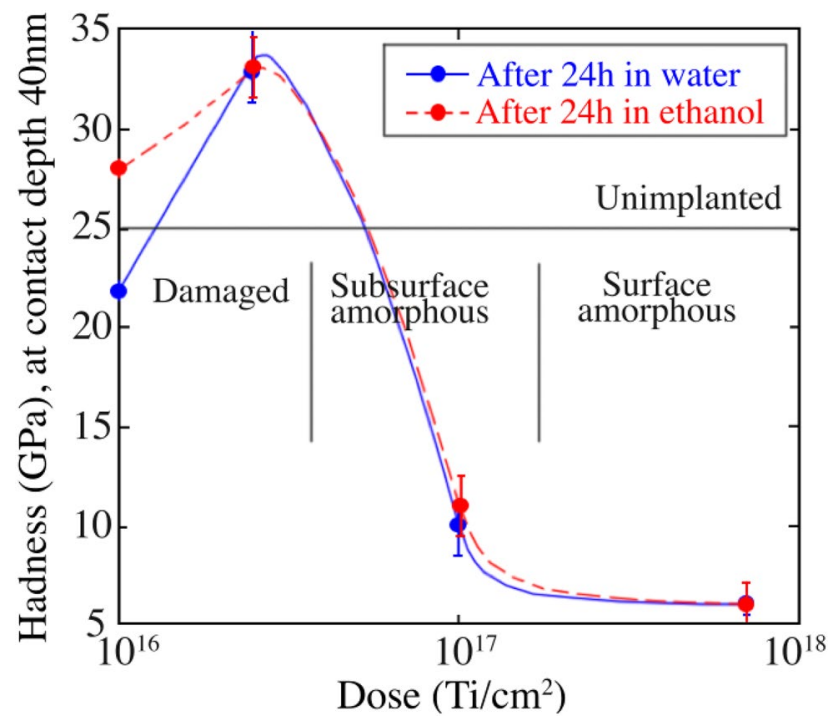

Fig. 4 Hardness at the contact depth $40 \mathrm{~nm}$ with respect to dose of various $\mathrm{Ti}^{+}$ion implantations in sapphire after water and ethanol exposure adsorbate-affected layer occurs on the surface of crystalline oxide materials of thickness up to 5-30 nm depending on the material and test environment [9]. This adsorbate softened layer is perhaps enhancing the crystal plasticity at near-surface region by increasing dislocation mobility which results in low hardness. In this study, our results show that after Ti implantation, the hardness is improved as compared to unimplanted sapphire and the chemomechanical effect is reduced. We postulate that this is due to the reduction in the amount of adsorbed water as previously seen for titaniumimplanted $\mathrm{MgO}$ [12].

To determine if a similar mechanism applies for ion implanted sapphire and if any substantial adsorbate-related phases are formed that are responsible for reducing the environmental sensitivity observed after exposure to water and ethanol, Raman spectroscopy can be utilised. To study the changes after titanium implantation into the surface, we kept the samples first in ethanol and then water for about $24 \mathrm{~h}$. The surface adsorption behaviour is obtained from in situ Raman in the same medium, i.e. there is a layer of water or ethanol covering the surface through which the Raman laser beam penetrates to analyse the surface so there will be a contribution to the measured spectrum from the liquid. The Raman spectra accumulated for all the samples in the range of $2500-3500 \mathrm{~cm}^{-1}$ are shown in Fig. 5 .

Figure 5a shows the Raman spectrum in the range about 2500-3500 $\mathrm{cm}^{-1}$, performed in air on unimplanted and implanted sapphire surfaces. The spectra have all been plotted to the same scale but have been displaced on the vertical axis for clarity. In this range the presence of a broad peak around $2950 \mathrm{~cm}^{-1}$, associated with vibrations of water molecules, is evidence of the presence of hydrogen-bonded $\mathrm{OH}$ groups. In the unimplanted sapphire, this peak is complicated, with two sharper peaks at $2857 \mathrm{~cm}^{-1}$ and $2920 \mathrm{~cm}^{-1}$. In the literature, there are suggestions that these peaks are due to the fact that the material may contain some internal hydrogen impurities in the form of $\mathrm{OH}$ due to its production method. The majority of this $\mathrm{OH}$ is expected to have diffused in from the outside physisorbed water molecules and; thus, it resides at or near the surface. The physisorbed water layer is hydrogen bonded to a thin layer of chemisorbed $\mathrm{OH}$ at the sapphire surface [9]. There are two other sharp peaks at about $2708 \mathrm{~cm}^{-1}$ and $2730 \mathrm{~cm}^{-1}$, corresponding to $\mathrm{CH}$ and CC stretching modes which are probably due to the presence of organic contamination on the surface. In contrast, implantation to the dose of $2 \times 10^{16} \mathrm{Ti}^{+} \mathrm{cm}^{-2}$, removes the sharp peaks including the $\mathrm{OH}$ peak due to the surface sputtering in the implantation process. As the dose is increased $\left(2.5 \times 10^{16} \mathrm{Ti}^{+} \mathrm{cm}^{-2}\right)$, a broad $\mathrm{OH}$ peak begins to appear. At both of these doses, the two other contamination peaks present in unimplanted sample spectra at about $2708 \mathrm{~cm}^{-1}$ and $2730 \mathrm{~cm}^{-1}$ are not observed. However, as the dose is increased further $\left(3.2 \times 10^{16} \mathrm{Ti}^{+} \mathrm{cm}^{-2}\right)$, the spectrum shows 
(a)

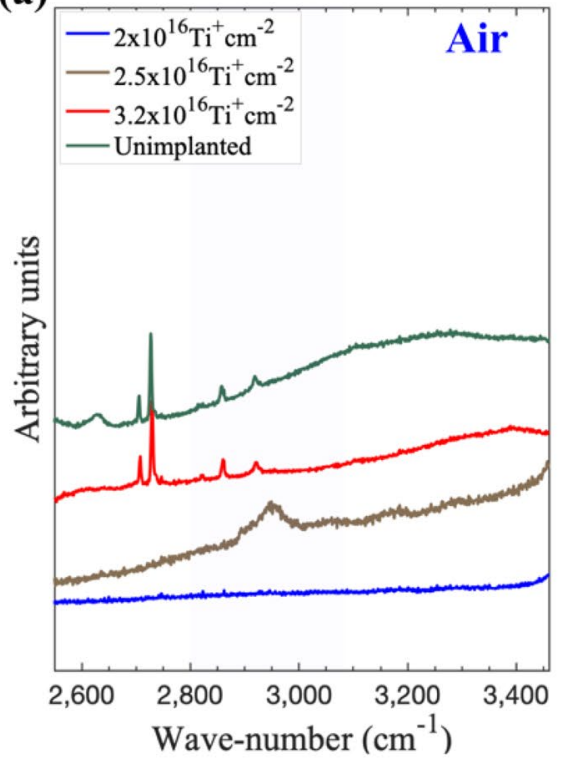

(b)

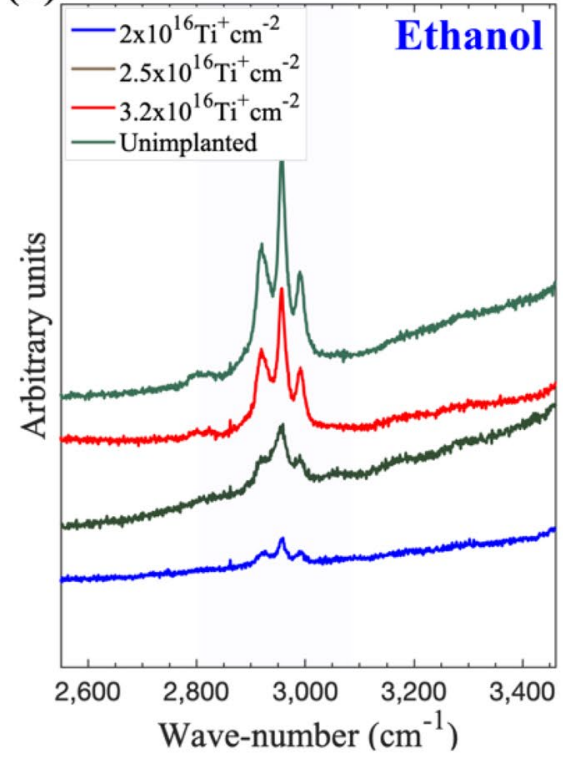

(c)

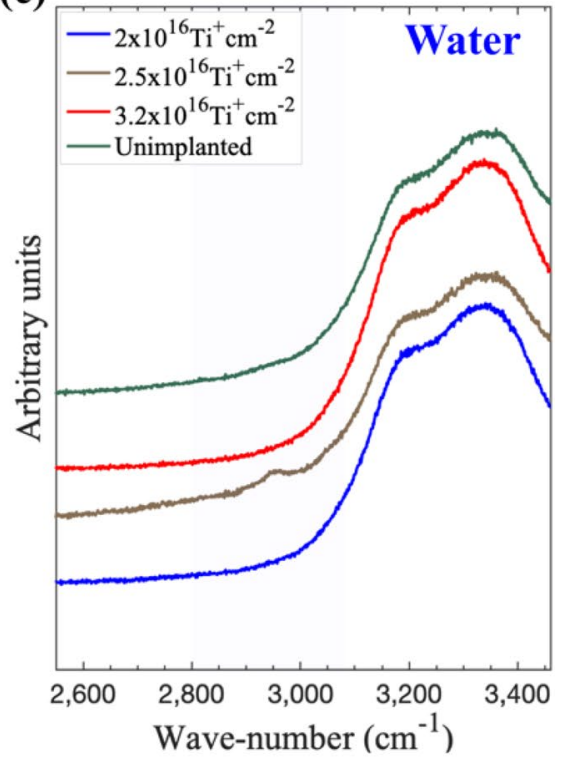

Fig. 5 Raman spectra of unimplanted and Ti-implanted sapphire in $\mathbf{a}$ air and after exposure to $\mathbf{b}$ ethanol and $\mathbf{c}$ water

the same behaviour as the unimplanted case except that the areas of the peaks are reduced. This occurs due to the presence of the water on the surface and indicates the physisorbed water is removed only at doses below $2.5 \times 10^{16} \mathrm{Ti}^{+}$ $\mathrm{cm}^{-2}$. The most important point to note that the peak areas significantly change for small changes in $\mathrm{Ti}^{+}$ion implantation dose.

Figure $5 \mathrm{~b}$ shows the Raman spectrum in the range about $2500-3500 \mathrm{~cm}^{-1}$, performed in ethanol on unimplanted and Ti- implanted sapphire surfaces whilst Fig. 5c shows the spectra from the same samples under water. From Fig. 5b it is clear that three sharp peaks from the liquid and surface species are visible around $2950 \mathrm{~cm}^{-1}$ (from adsorbed ethanol) and that physisorbed water is displaced and anything that remains produces a very broad shallow peak between 3100 and $3400 \mathrm{~cm}^{-1}$. In the unimplanted case, the ethanol peaks show relatively high intensity which is due to the high adsorbed ethanol concentration on the surface but this intensity is reduced after implantation. This implies that the implanted surface shows less propensity of adsorb ethanol as well as water. For implanted surfaces in the presence of ethanol at the dose of $2 \times 10^{16} \mathrm{Ti}^{+} \mathrm{cm}^{-2}$ only a small peak from adsorbed water exists. At the dose of $2.5 \times 10^{16} \mathrm{Ti}^{+} \mathrm{cm}^{-2}$, this water peak becomes slightly broader than at the dose of $2 \times 10^{16} \mathrm{Ti}^{+} \mathrm{cm}^{-2}$ but the area of the peak is unchanged (Fig. 6). Here further dose increases $\left(3.2 \times 10^{16} \mathrm{Ti}^{+} \mathrm{cm}^{-2}\right)$ show similar behaviour to the unimplanted specimens even after the exposure to ethanol (Fig. 5b). Thus, between these two doses $\left(2 \times 10^{16} \mathrm{Ti}^{+} \mathrm{cm}^{-2}\right.$ and $\left.2.5 \times 10^{16} \mathrm{Ti}^{+} \mathrm{cm}^{-2}\right)$ the broad peak at $3100-3400 \mathrm{~cm}^{-1}$ obtained in the presence of ethanol shows evidence of ethanol displacing water; the

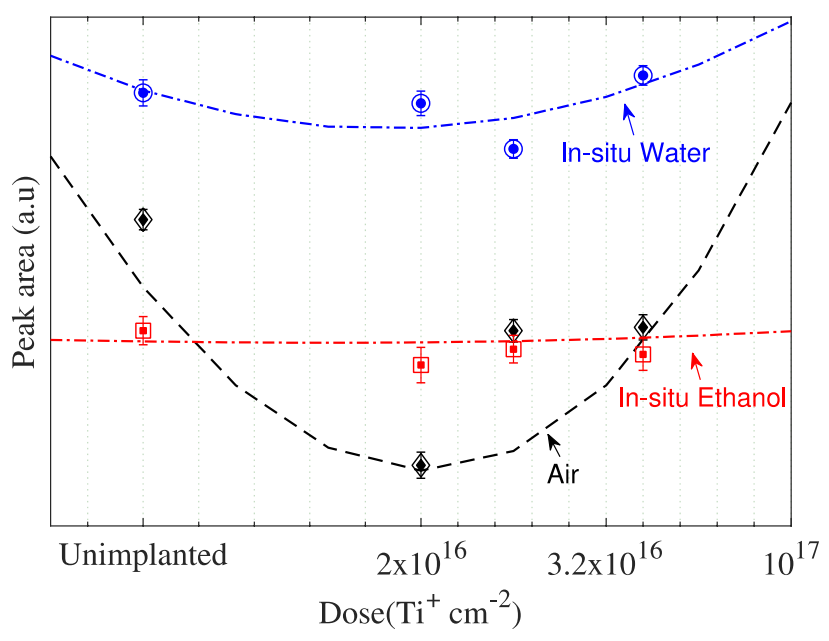

Fig. 6 Water peak area $\left(3000-3400 \mathrm{~cm}^{-1}\right)$ of unimplanted and Tiimplanted sapphire

reduced adsorbed water from the environment does not change appreciably with dose (Fig. 6).

Furthermore, in this dose range, the Raman data obtained for adsorbed water under water show similar behaviour (Fig. 5c); in comparison to unimplanted samples the intensity and the peak area are considerably reduced for the implanted samples in the dose range $2-2.5 \times 10^{16} \mathrm{Ti}^{+} \mathrm{cm}^{-2}$. This indicates the physisorbed water or ethanol layer is either completely removed or reduced after the implantation which is responsible for the increase in hardness. The fact that both ethanol and water adsorbates are affected indicates that this is not due to a specific chemical interaction but is a more 
general consequence of the implantation process. Indeed, we have found that implantation with a range of elements in the same ion implantation facility generates a similar result.

\subsection{Mechanism of Implantation-Induced Changes in Adsorbate Concentration}

Ion implantation creates defects by atomic collisions in the material and it is possible that these may contribute to the desorption process. The single crystal sapphire may contain a significant amount of dissolved water depending on how it is made and processed and this could create a partially compensated cation vacancy [12]. In this case, a single proton is associated with one oxygen ion surrounding a cation vacancy. Similar defects can occur where several $\mathrm{OH}^{-}$ions are associated with the vacancy, resulting in fully compensated (neutrally charged) and over compensated (negatively charged) defects, which inhibit the chemisorption process. However, at the high implantation energies used in this study the surface implanted ion and defect concentration is relatively low and sputtering processes will remove the surface of the implanted region including such defects so this mechanism is unlikely.

Significance difference in hardness of sapphire surface before implantation was observed when the contact depth was below $40 \mathrm{~nm}$ (Fig. 2), signifying chemomechanical softening as hardness is low because the surface become softer which is due to water adsorption layer on the surface. After implantation, hardness increases, associated that the chemomechanical softening of the surface is reduced after implantation and no adsorbed water layer was formed. For the physisorption to take place, a chemisorbed $\mathrm{OH}$ layer is required, the extent of which is partially reduced during implantation process and which is probably due to the formation of a stable, charge-neutral, surface structure during the implantation process itself. However, when implantation doses increase, hardness decreased that revealing the re-establishment of the adsorbed water layer when implanted by high doses. In this case, near-surface structural changes mainly driven by radiation damage in particular amorphization which enable the chemomechanical softening.

The localised charges needed for water chemisorption might have decreased by the surface segregation of the $\mathrm{Ti}^{+}$ implanted ions; the presence of transition metals can reduce $\mathrm{OH}^{-}$ions to molecular hydrogen and $\mathrm{O}^{2-}$ ions [12]. The reduction in $\mathrm{OH}^{-}$ions would reduce the amount of hydrogen bonding between surface $\mathrm{OH}$ and water molecules and therefore the amount of hydrogen bonded water would be dramatically reduced. This behaviour could explain why the reduction in both molecular water and $\mathrm{OH}$ seen in the Raman at dose of $2 \times 10^{16} \mathrm{Ti}^{+} \mathrm{cm}^{-2}$. This reduction in the water readsorption leads to a reduction of the chemomechanical effect. The removal of the chemomechanical effect is observed in the dose range of $2 \times 10^{16} \mathrm{Ti}^{+} \mathrm{cm}^{-2}-2.5 \times 10^{16}$ $\mathrm{Ti}^{+} \mathrm{cm}^{-2}$. Above these doses range $\left(2.5 \times 10^{16} \mathrm{Ti}^{+} \mathrm{cm}^{-2}\right)$, the chemomechanical effect is again seen but to a much smaller extent which is likely due to the near-surface structural changes driven by radiation damage, such as amorphisation.

The water drop contact angles were measured for unimplanted sapphire and the titanium implanted sapphire at three two different implantation doses. For unimplanted sapphire the contact angle was $67 \pm 3^{\circ}$ which is in the expected range for sapphire surfaces cleaned in water or alcohol. After implantation to $2.5 \times 10^{16} \mathrm{Ti}^{+} \mathrm{cm}^{-2}$, where the sapphire nearsurface layer is damaged but crystalline the contact angle increases to $95 \pm 5^{\circ}$ and the surface is clearly more hydrophobic. By the time that the amorphous layer has reached the surface, at a dose of $1.5 \times 10^{17} \mathrm{Ti}^{+} \mathrm{cm}^{-2}$ the contact angle has fallen to $79 \pm 3^{\circ}$ indicating an increase in hydrophilicity compared to the lose dose implantation but not to the same extent as the unimplanted sapphire. This mirrors the results for the changes in surface adsorbates in the previous section.

The charge state of implanted titanium in sapphire has been reported to be close to $3^{+}$under the conditions used here but between $3^{+}$and $4^{+}$[20]. There is also a tendency for titanium $3^{+}$and $4^{+}$ions to segregate to the surface in sapphire [27]. To identify the doping sites of Ti, XPS was carried out to characterise the surface chemical composition (Fig. 7).

The C $1 \mathrm{~S}$ and Ti 2P spectrum were fitted using Gaussian functions superimposed on a Shirley and linear background, respectively. A significant difference was observed in the C 1S core level peaks comparing the implanted and unimplanted sapphire samples. The $\mathrm{C} 1 \mathrm{~s}$ spectrum for adventitious carbon contamination typically has $\mathrm{C}=\mathrm{C}, \mathrm{C}-\mathrm{O}$ and $\mathrm{C}=\mathrm{O}$ components. Measurements for the unimplanted material were obtained on regions of the sapphire which had not been in the ion beam, but had been processed through the same vacuum cycle. For unimplanted sapphire the $\mathrm{C} 1 \mathrm{~S}$ peaks at $284.7 \mathrm{eV} 285.41$ and $286.1 \mathrm{eV}$ can be assigned to $\mathrm{C}=\mathrm{C}, \mathrm{C}-\mathrm{C}$ and C-O, respectively (Fig. 7e).

For the Ti implanted samples, the $\mathrm{C} 1 \mathrm{~S}$ peaks observed at the binding energy of $284.9 \mathrm{eV}$ and $286.42 \mathrm{eV}$ corresponding to $\mathrm{C}-\mathrm{C}$ and $\mathrm{C}-\mathrm{O}$ bonds are shown in Fig. $7 \mathrm{a}$ and c. In addition, there are peaks at around $286 \mathrm{eV}$ and $289 \mathrm{eV}$ which can be assigned to $\mathrm{C}=\mathrm{O}$ and $\mathrm{C}-\mathrm{O}-(\mathrm{OH})$ which are not present in the unimplanted sample spectra. Because the samples were kept in the same conditions between implantation and analysis it is unlikely that this is contamination issue and the changed surface chemistry arises from the implantation process. The Ti $2 \mathrm{P}$ peaks from the samples are summarised in Fig. $7 \mathrm{~b}, \mathrm{~d}$ and $\mathrm{f}$. The Ti $2 \mathrm{P}$ spectra of the $1 \times 10^{17} \mathrm{Ti}^{+}$ $\mathrm{cm}^{-2}$ showed the Ti $2 \mathrm{P}_{3 / 2}$ and Ti $2 \mathrm{P}_{1 / 2}$ intensity maxima at $458.86 \mathrm{eV}$ and $464.54 \mathrm{eV}$, respectively (Fig. $7 \mathrm{~b}$ ), whereas the Ti $2 \mathrm{P}$ spectra of the $3.2 \times 10^{16} \mathrm{Ti}^{+} \mathrm{cm}^{-2}$ has low intensity as the surface concentration is too small to observe (Fig. 7d). 
Fig. 7 a C 1S and b Ti 2P XPS spectra of sapphire implanted with $1 \times 10^{17} \mathrm{Ti}^{+} \mathrm{cm}^{-2}, \mathbf{c ~ C} 1 \mathrm{~S}$ and $\mathbf{d}$ Ti $2 \mathrm{P}$ XPS spectra of sapphire implanted with $3.2 \times 10^{16}$ $\mathrm{Ti}^{+} \mathrm{cm}^{-2}$ and $\mathbf{e} \mathrm{C} 1 \mathrm{~S}$ and $\mathbf{f} \mathrm{Ti} 2 \mathrm{P}$ XPS spectra of sapphire

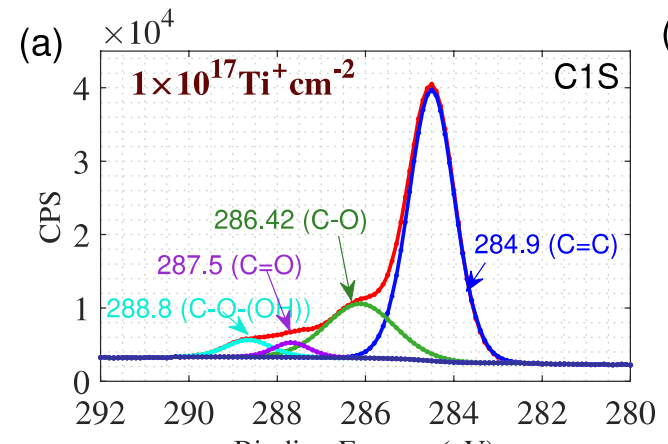

$$
\text { (c) }
$$

(c)
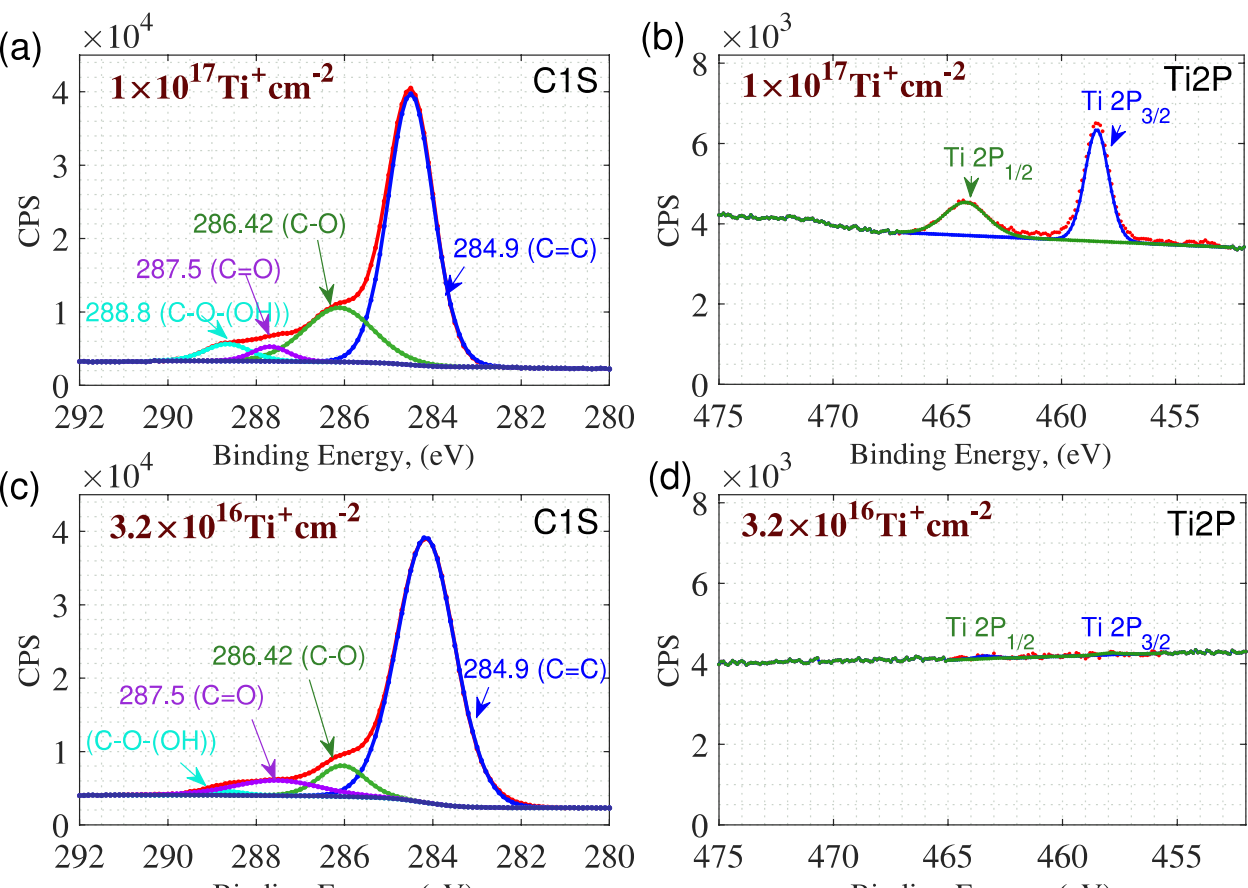

(e)
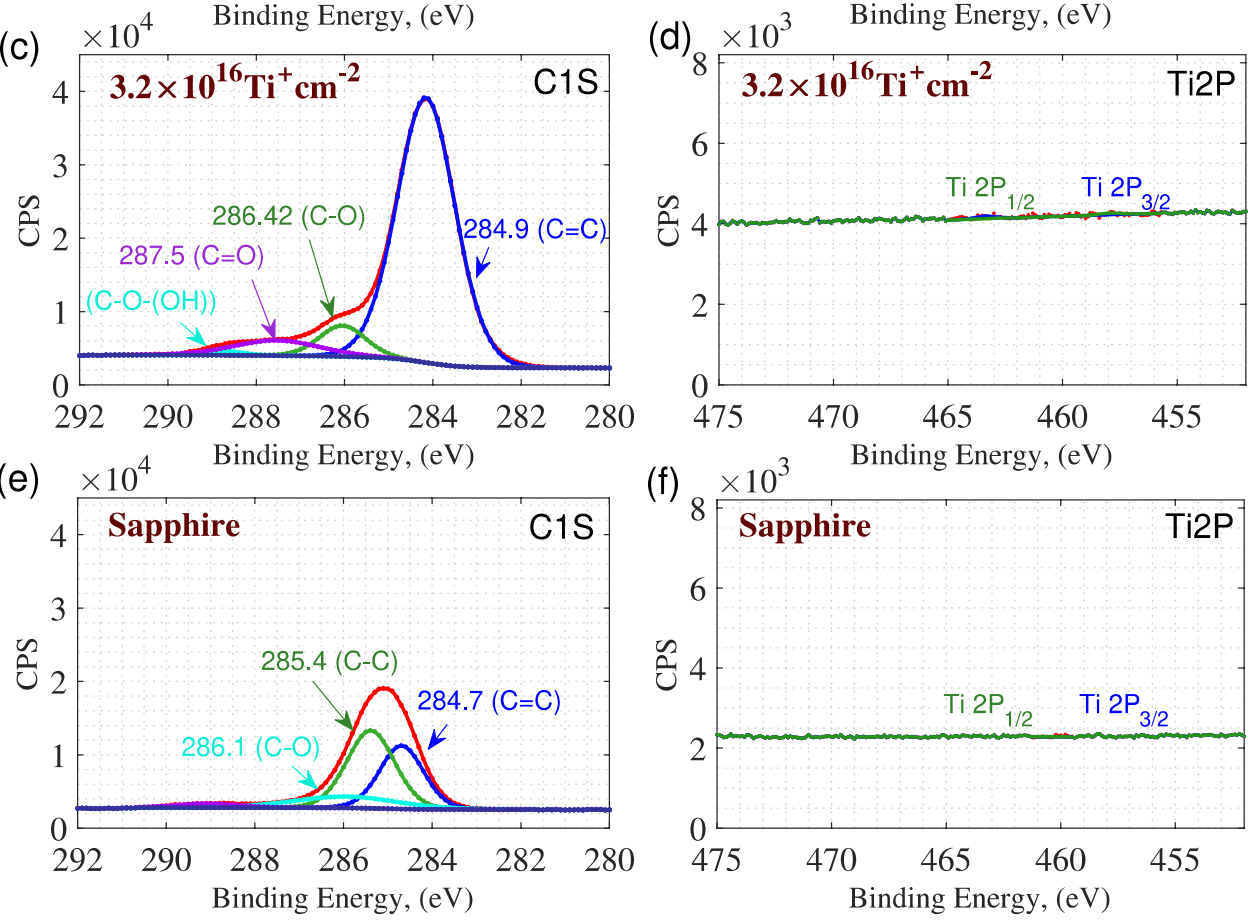

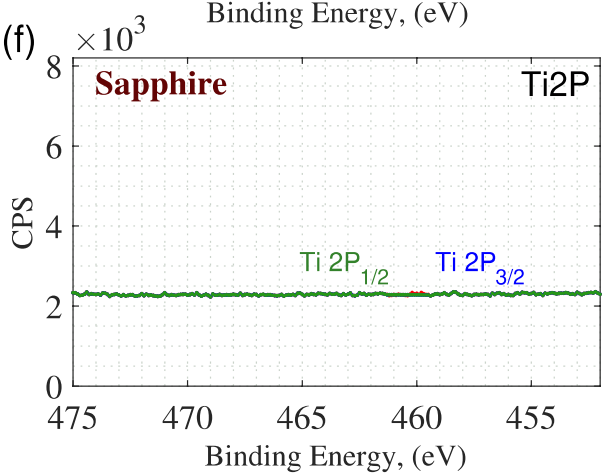

All the data indicate that it is the carbon at the surface which controls the surface adsorbate and chemomechanical behaviour rather than the defect state of the sapphire or the surface titanium concentration or charge state.

The chemomechanical effect due to long-term environmental sensitivity of the near-surface mechanical properties of various materials have studied from few decades [1, $9,28,29]$. For instance, properties, such as creep, fracture and fatigue are known to be susceptible to changes in environment [30, 31]. Also, in the context of bio-tribocorrosion studies, the degradation of Ti-based biomedical devices, such as wear and corrosion synergistic effect of are well known and widely studied [32-35]. The body fluid environment may also decrease the fatigue strength and Wear performance of the devices. Ion implantation has been used to reduce the friction and increase the wear resistance of a range of metallic and ceramic materials and has been used to improve the life of titanium metallic implants. It has the advantage that it is not a coating process and does not suffer issues of coating detachment in these applications. In this study we found the near-surfaces hardness is highly dependent on the Ti implanted dose and the environment is only important in a critical dose range. In addition, carbon impurity formation occurs due to a small amount of recoil- implantation and ion beam mixing that resulted in a highly stable carbonaceous layer at low doses [36, 37]. Thus, treating the surface with appropriate ion implanted species can control the near-surface hardness and reduce the chemomechanical effect which is required for optimum tribological performance. Implantation with a distinctive combination of ions to produce chemically-controlled, stable high strength surfaces is, as yet, unexplored and may offer a fruitful area for future studies.

The origin of the carbon is due to the interaction of the ion beam with carbon species depositing on the sapphire surface in the vacuum chamber. The sample chamber used in the Cockcroft-Walton facility was pumped by a diffusion pump to a base pressure of $10^{-6}$ Torr. Back-streaming of diffusion pump oil (Santovac 5-a five ring polyphenyl ether) leads to the deposition of carbon and oxygen containing 
species on the surface of the samples with an estimated layer thickness of a few nanometres. The ion beam deposits energy in inelastic collisions in the near-surface region resulting in bond breakage and structural rearrangement in the adsorbed layers. TRIM calculations for a $5 \mathrm{~nm}$ layer of diffusion pump oil on a sapphire surface irradiated with a $300 \mathrm{keV}$ titanium ion beam (Fig. 8) show considerable recoil damage in the oil layer (mainly carbon and hydrogen) and preferential sputtering of hydrogen. A small amount of recoil implantation and ion beam mixing occur introducing carbon into the top $1 \mathrm{~nm}$ of the sapphire surface. The highly reactive damaged material forms new bonds between the carbon in the surface layer and oxygen from the sapphire and contains only a small amount of implanted titanium. The result is a highly stable, non-polar, carbonaceous surface layer on top of a thin layer of carbon mixed into the sapphire which is created during the implantation process itself. The stability of the surface layer is evidenced by the fact that no change in properties or composition was observed even several years after the implantation.

The presence of $\mathrm{Ti}^{4+}$ in sapphire may also promote the formation of neutral defects at the surface which require no $\mathrm{OH}$ to be bonded to them in order to maintain the charge neutrality of the crystal [12], but this is a relatively small effect given the low surface titanium concentration at doses where the reduction in adsorbate concentration is most pronounced. The presence of a non-polar carbon layer on the sapphire surface will; thus, reduce adsorbate concentration and result in high hardness. High surface hardness is observed more for low doses (Figs. 3, 4) because the concentration of defects is not high enough to cause amorphisation but a non-polar surface is produced. In case of higher doses (above $~ 3 \times 10^{16} \mathrm{Ti}^{+} \mathrm{cm}^{-2}$ ) amorphisation occurs. The surface hardness is less above these doses because amorphous material is softer than crystalline material, but does not show

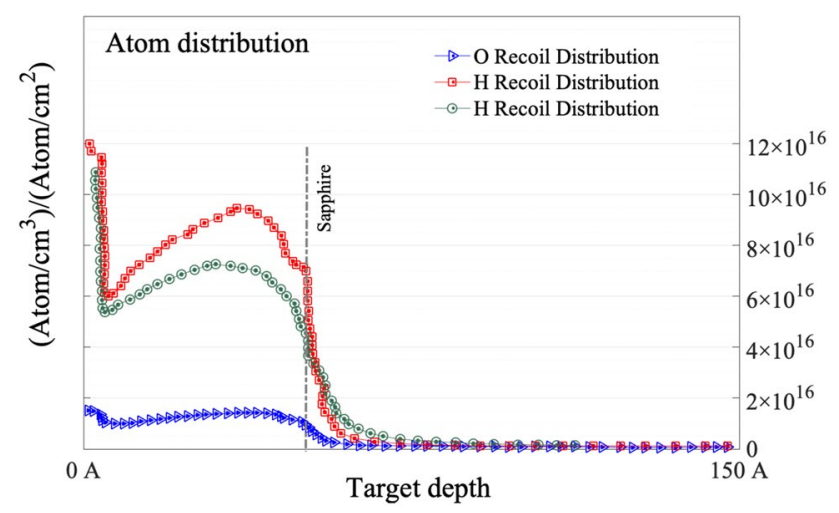

Fig. 8 TRIM calculation of the damage created by $300 \mathrm{keV}$ Titanium implantation of a $5 \mathrm{~nm}$ thick layer of Santovac 5 diffusion pump oil on sapphire. Considerable recoil damage of the oil layer is observed but the sapphire substrate remains substantially undamaged chemomechanical effects because such amorphous material does not support dislocation-based deformation mechanisms. The hardness is therefore highly dependent on the structural changes occurring at or near the surface due to radiation damage and amorphisation.

One implication of these results is that the effectiveness of any ion implantation treatment will depend on the ion implantation system used since the back-streamed carbon, a feature of the older machines used in this study, is much less in modern turbomolecular or cryo-pumped systems. If the major reason for use of the implantation treatment is to remove or reduce chemomechanical effects then this will no longer be as effective in modern treatment systems. The surface carbon doping due to the implantation process can be optimised to deliver the best performance and carbon-rich alumina surfaces produced by other techniques might be a good avenue of future development.

\section{Conclusions}

The removal of environmentally softened layers on the sapphire surface after low dose $\mathrm{Ti}^{+}$ion implantation has been demonstrated. It has been shown to result in improving nearsurface hardness by reducing chemomechanical effects. The low load hardness of sapphire is influenced by the dose of $\mathrm{Ti}^{+}$ion implantation in a complex manner. Implantation is found to increase the hardness up to the onset of amorphisation $\left(\sim 3 \times 10^{16} \mathrm{Ti}^{+} \mathrm{cm}^{-2}\right)$ whilst at higher doses hardness is reduced. The increase in near-surface hardness is partly due to the removal of physisorbed water which promotes chemomechanical softening of the sapphire substrate. In situ Raman scattering measurement has revealed the removal of the water adsorbate layer at low doses and existence of the readsorbed water after surface amorphisation at high doses. The removal of the adsorbed water layer is due to the formation of a non-polar, carbonaceous layer on the sapphire surface by ion beam cracking of adsorbed diffusion pup oil. Based on this study, it is concluded that the ion implantation with an appropriate ion species can control the chemomechanical effects and therefore can control the surface mechanical properties of sapphire.

Acknowledgements NM acknowledges the support of EPSRC for her part of this project through the REC-ASM Grant. This work was also funded by the EPSRC through the NECEM Grant.

\section{Compliance with Ethical Standards}

Conflict of interest There are no conflicts of interest associated with the submission of this manuscript. Part of the work was previously presented as a conference paper for MS\&T2018 but has been extended here to provide extra supporting evidence regarding the mechanisms for the effect of ion implantation discussed. 
Open Access This article is licensed under a Creative Commons Attribution 4.0 International License, which permits use, sharing, adaptation, distribution and reproduction in any medium or format, as long as you give appropriate credit to the original author(s) and the source, provide a link to the Creative Commons licence, and indicate if changes were made. The images or other third party material in this article are included in the article's Creative Commons licence, unless indicated otherwise in a credit line to the material. If material is not included in the article's Creative Commons licence and your intended use is not permitted by statutory regulation or exceeds the permitted use, you will need to obtain permission directly from the copyright holder. To view a copy of this licence, visit http://creativecommons.org/licenses/by/4.0/.

\section{References}

1. Westwood ARC, Huntington RD, Macmillan NH (1973) Influence of environment on the mobility of near-surface dislocations in ionic crystals. J Appl Phys 44:5194-5195. https://doi. org/10.1063/1.1662125

2. Czernuszka JT, Page TF (1985) The importance of microscopy in studying the wear behaviour of ceramic surfaces. J Microsc 140:159-169. https://doi.org/10.1111/j.1365-2818.1985.tb026 72. $\mathrm{x}$

3. Westwood ARC, Macmillan NH, Kalyoncu RS (1973) Environment-sensitive hardness and machinability of $\mathrm{Al}_{2} \mathrm{O}_{3}$. J Am Ceram Soc 56:258-262. https://doi.org/10.1111/j.1151-2916.1973.tb124 83. $\mathrm{x}$

4. Macmillan NH, Huntington RD, Westwood ARC (1974) Chemomechanical control of sliding friction behaviour in non-metals. $\mathrm{J}$ Mater Sci 9:697-706. https://doi.org/10.1007/BF00761789

5. Westwood ARC, Ahearn JS, Mills JJ (1981) Developments in the theory and application of chemomechanical effects. Colloids Surf 2:1-35. https://doi.org/10.1016/0166-6622(81)80050-9

6. Hanneman RE, Westbrook JH (1968) Effects of adsorption on the indentation deformation of non-metallic solids. Philos Mag 18:73-88. https://doi.org/10.1080/14786436808227310

7. Czernuszka JT, Pages TF (1987) Characterizing the surface contact behaviour of ceramics. J Mater Sci 22:3907-3916. https://doi. org/10.1007/BF01133339

8. Hainsworth SV, Page TF (1994) Nanoindentation studies of the chemomechanical effect in sapphire. J Mater Sci 29:5529-5540. https://doi.org/10.1007/BF00349944

9. Bull SJ, Moharrami N, Hainsworth SV, Page TF (2016) The origins of chemomechanical effects in the low-load indentation hardness and tribology of ceramic materials. J Mater Sci 51:107-125. https://doi.org/10.1007/s10853-015-9412-3

10. Hainsworth SV, Page TF (1994) Nanoindentation studies of chemomechanical effects in thin film coated systems. Surf Coat Technol 68:571-575. https://doi.org/10.1016/0257-8972(94)90219-4

11. Burnett PJ, Page TF (1985) Chemomechanical effect in ionimplanted magnesium oxide. J Mater Sci Lett 4:1364-1370. https ://doi.org/10.1007/BF00720103

12. Bull SJ, Page TF (1989) Chemomechanical effects in ionimplanted MgO. J Phys Appl Phys 22:941. https://doi. org/10.1088/0022-3727/22/7/009

13. Hartley NEW (1975) Ion implantation and surface modification in tribology. Wear 34:427-438. https://doi.org/10.1016/00431648(75)90109-X

14. Rehbinder P (1931) Verminderung der Ritzhärte bei Adsorption grenzflächenaktiver Stoffe. Z Für Phys 72:191-205. https://doi. org/10.1007/BF01341906
15. Sasaki S (1989) The effects of the surrounding atmosphere on the friction and wear of alumina, zirconia, silicon carbide and silicon nitride. Wear 134:185-200. https://doi.org/10.1016/00431648(89)90068-9

16. Westwood ARC, Goldheim DL, Lye RG (1967) Rebinder effects in MgO. Philos Mag 16:505-519. https://doi.org/10.1080/14786 436708220861

17. Burnett PJ, Page TF (1987) The friction and hardness of ion-implanted sapphire. Wear 114:85-96. https://doi. org/10.1016/0043-1648(87)90018-4

18. Ohkubo M, Hioki T, Kawamoto J (1986) Recrystallizationdriven migration of implanted ions in sapphire and resultantoriented precipitation. J Appl Phys 60:1325-1335. https://doi. org/10.1063/1.337305

19. Burnett PJ, Page TF (1984) Surface softening in silicon by ion implantation. J Mater Sci 19:845-860. https://doi.org/10.1007/ BF00540455

20. Bourdillon AJ, Bull SJ, Burnett PJ, Page TF (1986) The charge state of titanium ions implanted into sapphire: an EXAFS investigation. J Mater Sci 21:1547-1552. https://doi.org/10.1007/BF011 14707

21. Naramoto H, White CW, Williams JM et al (1983) Ion implantation and thermal annealing of $\alpha-\mathrm{Al} 2 \mathrm{O} 3$ single crystals. J Appl Phys 54:683-698. https://doi.org/10.1063/1.332076

22. Weber WJ (2000) Models and mechanisms of irradiation-induced amorphization in ceramics. Nucl Instrum Methods Phys Res Sect B 166:98-106. https://doi.org/10.1016/S0168-583X(99)00643-6

23. Bull SJ, Page TF, Yoffe EH (1989) An explanation of the indentation size effect in ceramics. Philos Mag Lett 59:281-288. https:// doi.org/10.1080/09500838908206356

24. Bull SJ (2003) On the origins and mechanisms of the indentation size effect. Z Für Met 94:787-792. https://doi. org/10.3139/146.030787

25. Fischer TE, Anderson MP, Jahanmir S, Salher R (1988) Friction and wear of tough and brittle zirconia in nitrogen, air, water, hexadecane and hexadecane containing stearic acid. Wear 124:133148. https://doi.org/10.1016/0043-1648(88)90240-2

26. Bull S, Yadav A (2018) The effect of thin carbon and chemomechanically softened layers on the near surface mechanical properties of sapphire tested by nanoindentation. In: Contributed papers from MS\&T17. MS\&T18, pp 1462-1469

27. Alombert-Goget G, Li H, Faria J et al (2016) Titanium distribution in Ti-sapphire single crystals grown by Czochralski and Verneuil technique. Opt Mater 51:1-4. https://doi.org/10.1016/j. optmat.2015.11.016

28. Dalmau Borras A, Roda Buch A, Rovira Cardete A et al (2019) Chemo-mechanical effects on the tribocorrosion behavior of titanium/ceramic dental implant pairs in artificial saliva. Wear 426-427:162-170. https://doi.org/10.1016/j.wear.2018.12.052

29. Mu L, Lin R, Xu R et al (2018) Oxygen release induced chemomechanical breakdown of layered cathode materials. Nano Lett 18:3241-3249. https://doi.org/10.1021/acs.nanolett.8b01036

30. Ramírez FMG, de Moura MFSF, Moreira RDF, Silva FGA (2020) A review on the environmental degradation effects on fatigue behaviour of adhesively bonded joints. Fatigue Fract Eng Mater Struct 43:1307-1326. https://doi.org/10.1111/ffe.13239

31. Suo Y, Yang X, Shen S (2015) Residual stress analysis due to chemomechanical coupled effect, intrinsic strain and creep deformation during oxidation. Oxid Met 84:413-427. https://doi. org/10.1007/s11085-015-9562-3

32. Dini C, Costa RC, Sukotjo C et al (2020) Progression of biotribocorrosion in implant dentistry. Front Mech Eng. https://doi. org/10.3389/fmech.2020.00001

33. Noumbissi S, Scarano A, Gupta S (2019) A literature review study on atomic ions dissolution of titanium and its alloys in implant dentistry. Materials 12:368. https://doi.org/10.3390/ma12030368 
34. Villanueva J, Trino L, Thomas J et al (2016) Corrosion, tribology, and tribocorrosion research in biomedical implants: progressive trend in the published literature. J Bio- Tribo-Corros 3:1. https:// doi.org/10.1007/s40735-016-0060-1

35. Bull SJ, Moharrami N, Langton D (2016) Mechanistic study of the wear of ceramic heads by metallic stems in modular implants. J Bio- Tribo-Corros 3:7. https://doi.org/10.1007/s4073 5-016-0066-8

36. Wang J, Toloczko MB, Kruska K et al (2017) Carbon contamination during ion irradiation - accurate detection and characterization of its effect on microstructure of ferritic/martensitic steels. Sci Rep 7:15813. https://doi.org/10.1038/s41598-017-15669-y
37. Gigax JG, Aydogan E, Chen T et al (2015) The influence of ion beam rastering on the swelling of self-ion irradiated pure iron at $450{ }^{\circ} \mathrm{C}$. J Nucl Mater 465:343-348. https://doi.org/10.1016/j. jnucmat.2015.05.025

Publisher's Note Springer Nature remains neutral with regard to jurisdictional claims in published maps and institutional affiliations. 